\title{
Discussing Opioid Risks With Patients to Reduce Misuse and Abuse: Evidence From 2 Surveys
}

Joachim O. Hero, MPH

Caitlin McMurtry, $S M^{2}$

Jobn Benson, $\mathrm{MA}^{2}$

Robert Blendon, $S_{c} D^{2}$

'Interfaculty Initiative in Health Policy,

Harvard University, Boston, Massachusetts

${ }^{2}$ Department of Health Policy and Management, Harvard T.H. Chan School of Public Health, Boston, Massachusetts
Conflicts of interest: authors report none.

\section{CORRESPONDING AUTHOR}

Joachim O. Hero, MPH

47R Jamaica St, \#1

Boston, MA 02130

Hero@fas.harvard.edu

\begin{abstract}
We used 2 population-representative surveys to evaluate the recommendation from recent clinical guidelines for prescribing opioid analgesics that physicians discuss the risk of long-term use disorders with patients. In nationally representative data we observed a $60 \%$ lower rate, after adjustment for covariates, in a self-reported saving of pills among respondents who say they talked with their physicians about the risks of prescription painkiller addiction (67\% lower rate without adjustment). These findings suggest patient education efforts, as currently practiced in the United States, may have positive behavioral consequences that could lower the risks of prescription painkiller abuse. Future research should test these associations under controlled settings.
\end{abstract}

Ann Fam Med 2016;14:575-577. doi: 10.1370/afm.1994

\section{INTRODUCTION}

$\mathrm{n}$ its recently published guidelines for prescribing opioids for chronic pain, the Centers for Disease Control and Prevention (CDC) recommend that clinicians discuss the known risks and benefits of opioid therapy with their patients. ${ }^{1}$ Recommended topics of discussion include the risks of life-long use disorders and the risk posed to family members if prescription painkillers are intentionally or unintentionally shared. Although communication-based techniques have been shown to improve patient behaviors, ${ }^{2}$ the CDC guidelines note that no evidence currently exists to evaluate the effectiveness of patient education or any other risk-mitigation strategies for prescription opioids. Given the increasing demands placed on physicians in primary care, evidence will be essential to helping physicians prioritize as they put these guidelines into practice. We evaluated 2 population-representative surveys conducted in 2015 and found preliminary evidence that suggests patient education efforts as currently practiced may be having positive behavioral consequences.

\section{METHODS}

We analyzed the results of 2 random-digit-dial telephone surveys of adults aged 18 years and older conducted by the Harvard T. H. Chan School of Public Health and the Boston Globe: a national poll fielded April 15-19, 2015 (an 8\% response rate yielded 1,033 completed interviews) and a Massachusetts poll fielded April 7-16, 2015 (a 15\% response rate yielded 810 completed interviews). Both surveys included cellular and landline telephones and were poststratified to US Census benchmarks of age, sex, education, race, marital status, and geographic area to be representative of underlying populations (The United States and Massachusetts, respectively). Samples were restricted to respondents who reported that they had been prescribed strong prescription painkillers within the last 2 years, bringing final sample sizes to 216 in the national survey, and 169 in the Massachusetts sample. We provide the survey instrument in the Supplemental Appendix, available at http://www.annfammed.org/content/14/6/575/suppl/DC1. 
We fit multivariable logistic regressions to estimate the association between reporting having talked with a physician about the risk of prescription painkiller addiction ("discussed risk of addiction") and reporting having saved prescription painkillers for personal medical use or to share with family members ("saved pills for later"). Retention of unused pills has been found to be an important source of opioid diversion and misuse. ${ }^{3-5}$ Control variables included sex, age, race, income, metro status, and geographic region. Models also controlled for whether the patient knew someone who abused prescription painkillers in the past 5 years, a marker associated with higher risk of abuse in the patient, ${ }^{6}$ to indirectly reduce bias that may occur from physicians targeting high-risk patients for discussion about addiction. All analyses were conducted in $\mathrm{R}^{7}$ using the survey (R 3.31) $)^{8}$ and effects (R 3.1-1) ${ }^{9}$ packages. (Model outputs can be viewed in Table A1 of the Supplemental Appendix.) Unadjusted results were also included for comparison. Model parameters were used to plot estimated response levels and $95 \%$ confidence intervals for comparison categories when holding all covariates constant at sample means. To test the sensitivity of our results to model specification, we systematically fit alternate specifications, including models specified through backward selection, and our conclusions were unaffected (data not shown).

\section{RESULTS}

National and Massachusetts samples were similar along sociodemographic characteristics, with the exception of metropolitan status, where the Massachusetts sample had higher proportions of respondents living in areas with suburban census designations. Residents in Massachusetts were far less likely than the broader US population to recall talking about the risk of prescription drug addiction (36\% recalled such a conversation compared with $61 \%$ nationally) and were more likely to say they saved pills for later use (30\% said they saved pills compared with $17 \%$ nationally, Table 1 ).

National respondents who reported discussing the risks of addiction were less likely to report saving prescription painkillers for later. Holding other covariates at national sample means, we estimated that $20 \%$ of respondents who did not remember discussing addiction risk reported saving pills for later, compared with only $8 \%$ who did remember discussing addiction risk, for a rate that is $60 \%$ lower. Without adjustment for covariates we observed an even larger difference of $27 \%$ compared with $9 \%$, respectively (Figure 1 ).

These results were reproduced in the Massachusetts sample. Holding other covariates at state sample means, we estimated that $26 \%$ of respondents who did not discuss the risk of addiction reported saving pills for later, compared with only $12 \%$ among those who did. Without adjustment for covariates we observed a difference of $36 \%$ compared with $19 \%$, respectively (Figure 1).

\section{DISCUSSION}

Even though patient education efforts figure prominently into the CDC's latest recommendations around opioid prescribing for chronic pain, evidence is sorely

\section{Table 1. Characteristics of Patients With Prescription Painkillers in National and Massachusetts Samples}

\begin{tabular}{|c|c|c|}
\hline Characteristic & $\begin{array}{l}\text { National } \\
\text { Data }\end{array}$ & $\begin{array}{c}\text { Massachusetts } \\
\text { Data }\end{array}$ \\
\hline Sample size, No. & 216 & 169 \\
\hline \multicolumn{3}{|l|}{ Sex, \% } \\
\hline Female & 59.2 & 54.1 \\
\hline Male & 40.8 & 45.9 \\
\hline \multicolumn{3}{|l|}{ Age, \% } \\
\hline$<30 y$ & 17.9 & 21.4 \\
\hline $30-64 y$ & 66.2 & 63.1 \\
\hline$\geq 65 y$ & 15.8 & 15.5 \\
\hline \multicolumn{3}{|l|}{ Race, \%a } \\
\hline White non-Hispanic & 66.6 & 79.9 \\
\hline Black non-Hispanic & 11.2 & 4.4 \\
\hline Hispanic & 14.5 & 10.1 \\
\hline Other & 7.8 & 5.6 \\
\hline \multicolumn{3}{|l|}{ Income, \% } \\
\hline Low & 25.2 & 29.1 \\
\hline Middle low & 30 & 24.5 \\
\hline Middle high & 22.3 & 19 \\
\hline High & 22.5 & 27.5 \\
\hline \multicolumn{3}{|l|}{ Metro area, \%b } \\
\hline Urban & 52.3 & 20.9 \\
\hline Rural & 25.3 & 2.5 \\
\hline Suburban & 22.4 & 76.6 \\
\hline \multicolumn{3}{|l|}{ Region, \% } \\
\hline Northeast & 19.4 & $\ldots$ \\
\hline North Central & 26.2 & $\ldots$ \\
\hline South & 34.9 & $\ldots$ \\
\hline West & 19.5 & $\ldots$ \\
\hline \multicolumn{3}{|c|}{ Know someone who abused opioids in last 5 years, \% } \\
\hline Yes & 47.3 & 41.9 \\
\hline No & 52.7 & 58.1 \\
\hline \multicolumn{3}{|c|}{ Discussed risk of addiction with physician, \% ${ }^{b}$} \\
\hline Yes & 60.5 & 36.2 \\
\hline No & 39.5 & 63.8 \\
\hline \multicolumn{3}{|l|}{ Saved pills for later, $\% c$} \\
\hline Yes & 16.8 & 29.9 \\
\hline No & 83.2 & 70.1 \\
\hline \multicolumn{3}{|c|}{$\begin{array}{l}\text { a } P<.1 . \\
\text { b } P<.001 \text { (groupwise } \chi^{2} \text { tests between samples). } \\
\text { c } P<.01 .\end{array}$} \\
\hline
\end{tabular}




\section{Figure 1. Saving prescription painkillers for later by recollection of addiction discussion.}

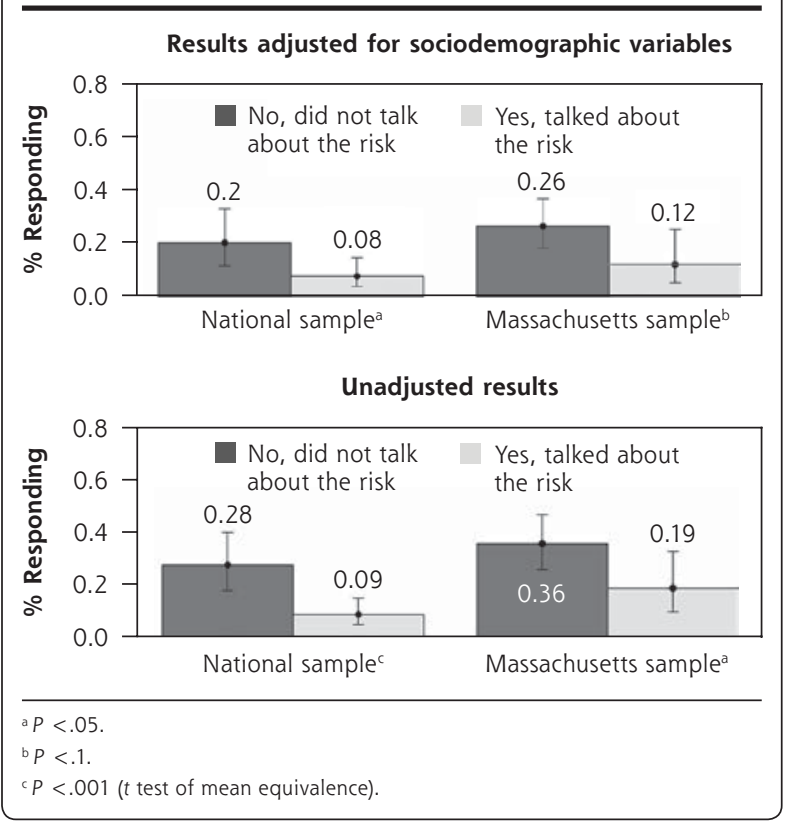

needed to support their use and identify best practices. Our findings suggest that, as currently practiced, physician efforts to talk with their patients about the addictiveness of prescription painkillers-or other topics addressed in the course of these discussions-may be yielding positive behavioral consequences that reduce opportunities for painkiller abuse.

Our data are cross-sectional, limited in sample size, and subject to many of the short-comings of survey data. The associations that we observe do not prove a causal relationship and could be explained by uncontrolled differences between patients who did and did not recall discussing the risk of addiction with their physicians. These findings, however, offer a first look at evidence to support a common recommendation from opioid prescribing guidelines for which no evidence currently exists and suggest that future exploration into the effectiveness of physician-patient communication on the risks of opioids may be fruitful. Future research should use controlled settings to test the effectiveness of a discussion about addiction risk and related safety measures in promoting appropriate use, storage, and disposal of prescription painkillers.

To read or post commentaries in response to this article, see it online at http://www.annfammed.org/content/14/6/575.

Key Words: survey research; substance abuse; opiate addiction; clinical practice guideline; best practices; communication

Submitted April 22, 2016; submitted, revised, June 28, 2016; accepted July 14, 2016.

Funding support: Research reported in this publication was supported by the National Institute of Mental Health of the National Institutes of Health under Award Number T32MH019733.

Disclaimer: The content is solely the responsibility of the authors and does not necessarily represent the official views of the National Institutes of Health.

Acknowledgments: The authors would like to thank Alan M. Zaslavsky PhD, at Harvard Medical School, for helpful comments and suggestions.

Supplementary materials: Available at http://www.AnnFamMed. org/content/14/6/575/suppl/DC1/.

\section{References}

1. Dowell D, Haegerich TM, Chou R. CDC guideline for prescribing opioids for chronic pain-United States, 2016. JAMA. 2016; 315(15)1624-1645.

2. Greene J, Hibbard JH, Alvarez C, Overton V. Supporting patient behavior change: approaches used by primary care clinicians whose patients have an increase in activation levels. Ann Fam Med. 2016;14(2):148-154.

3. Shrank WH. Our bulging medicine cabinets-the other side of medication nonadherence. N Engl J Med. 2011;364(17):1591-1593.

4. Lewis ET, Cucciare MA, Trafton JA. What do patients do with unused opioid medications? Clin J Pain. 2014;30(8):654-662.

5. Inciardi JA, Surratt HL, Kurtz SP, Cicero TJ. Mechanisms of prescription drug diversion among drug-involved club- and street-based populations. Pain Med. 2007;8(2):171-183.

6. Galea S, Nandi A, Vlahov D. The social epidemiology of substance use. Epidemiol Rev. 2004;26:36-52.

7. R Core Team (2016). R: A language and environment for statistical computing. R Foundation for Statistical Computing, Vienna, Austria. URL https://www.R-project.org/.

8. Lumley T. Analysis of complex survey samples. J Stat Softw. 2004; 9(8):1-19.

9. Fox J. Effect displays in R for generalised linear models. J Stat Softw. 2003;8(15):1-27. 